\title{
Utilizing Gravity in Movement-Based Games and Play
}

\author{
Perttu Hämäläinen $^{\alpha} \quad$ Joe Marshall $^{\beta} \quad$ Raine Kajastila $^{\alpha} \quad$ Richard Byrne $^{\gamma} \quad$ Florian 'Floyd' Mueller $^{\gamma}$ \\ ${ }^{\alpha}$ Dept. of Computer Science \\ Aalto University \\ firstname.lastname@aalto.fi \\ ${ }^{\beta}$ Mixed Reality Lab \\ Univ. of Nottingham \\ ${ }^{\gamma}$ Exertion Games Lab \\ RMIT University \\ joe.marshall@nottingham.ac.uk\{rich,floyd\}@exertiongameslab.org
}

\begin{abstract}
This paper seeks to expand the understanding of gravity as a powerful but underexplored design resource for movement-based games and play. We examine how gravity has been utilized and manipulated in digital, physical, and mixed reality games and sports, considering five central and gravity-related facets of user experience: realism, affect, challenge, movement diversity, and sociality. For each facet, we suggest new directions for expanding the field of movement-based games and play, for example through novel combinations of physical and digital elements.

Our primary contribution is a structured articulation of a novel point of view for designing games and interactions for the moving body. Additionally, we point out new research directions, and our conceptual framework can be used as a design tool. We demonstrate this in 1) creating and evaluating a novel gravity-based game mechanic, and 2) analyzing an existing movement-based game and suggesting future improvements.
\end{abstract}

\section{Author Keywords}

Gravity; movement-based games; exertion games; exergames; game design; bodily interaction.

\section{ACM Classification Keywords}

H.5.2. Information interfaces and presentation (e.g., HCI): User Interfaces.

\section{INTRODUCTION}

Designing for the moving body is an increasingly active area of HCI research. Following the proliferation of lowcost sensors and increasing computing capability, early research into bodily games and HCI (e.g., [26]) has evolved into a diverse and vibrant field of research and practice. Yet, we are only beginning to understand the moving body in conjunction with technology, considering aspects such as the reciprocal connection between body movement and

\footnotetext{
Permission to make digital or hard copies of all or part of this work for personal or classroom use is granted without fee provided that copies are not made or distributed for profit or commercial advantage and that copies bear this notice and the full citation on the first page. Copyrights for components of this work owned by others than the author(s) must be honored. Abstracting with credit is permitted. To copy otherwise, or republish, to post on servers or to redistribute to lists, requires prior specific permission and/or a fee. Request permissions from Permissions@acm.org.

CHI PLAY 2015, October 03 - 07, 2015, London, United Kingdom

Copyright is held by the owner/author(s). Publication rights licensed to ACM.

ACM 978-1-4503-3466-2/15/10 ...\$15.00

DOI: http://dx.doi.org/10.1145/2793107.2793110
}

emotion [6], and the effect of virtual representations (avatars) on the user [47].

In this paper, we aim to promote the understanding of gravity, which both constrains human movement and creates meaningful complexity and challenge. Virtual gravity has been used in games and simulations at least since Spacewar, one of the earliest computer games developed in 1962 [1]. Spacewar demonstrated how simple simulations of Newtonian mechanics can lead to the emergence of interesting and complex gameplay. In bodily $\mathrm{HCI}$ and movement-based games ${ }^{1}$, real gravity affects the user, the effects of which we believe are underexplored. We argue that the role of gravity is becoming more complex as gameplay evolves from seated to standing and ultimately all other modalities of balancing and moving, as illustrated in Figure 1. The snowboarding image was chosen to illustrate how 1) living-room movement-based games often pale in comparison to real-life sports, 2) defying gravity is often central to such vivid experiences, and 3) HCI in such experiences is still in its infancy (e.g., [32]).



Figure 1. Varying degrees of embodiment and movement in entertainment experiences, ranging from passive spectatorship to active bodily participation.

Gravity is central to the human experience; our earliest experiences of mastery stem from overcoming gravity as we learn to stand, walk, and jump, and falling (succumbing to gravity) has been found to be the most common nightmare type [41]. Gravity also emerged as the unifying theme at a workshop where the authors discussed their various projects related to movement-based games and bodily interaction (e.g., $[18,23,24,30,31,36])$. We

\footnotetext{
${ }^{1}$ By movement-based games we denote digital games where gross motor bodily input plays a central role [35]
} 


\begin{tabular}{|c|c|c|c|}
\hline & Digital & Physical & Mixed-reality \\
\hline Realism & $\begin{array}{l}\text { Simulated physics (Newtonian mechanics) } \\
\text { in video games since Spacewar (1962). } \\
\text { Exaggerated physics in platformers since } \\
\text { early } 80 \text { 's (e.g., Mario Bros [52]). }\end{array}$ & $\begin{array}{l}\text { Antigravity harnesses for rehabilitation } \\
\text { after back injuries. Exoskeletons for } \\
\text { reducing the weight of lifted objects. } \\
\text { Circus, stunt and sport equipment for } \\
\text { fighting and manipulating gravity, e.g. } \\
\text { trampolines, flying harnesses \& wires, } \\
\text { stilts, vertical wind tunnels. }\end{array}$ & $\begin{array}{l}\text { Illusion of altered gravity in various } \\
\text { simulators using actuated seats, cockpits, and } \\
\text { even rollercoasters [3]. Various exergames } \\
\text { where the user is standing but the avatar is } \\
\text { flying, swimming, floating in space [17, 53]. } \\
\text { Manipulating gravity and movement in both } \\
\text { real and virtual worlds, e.g., Kinect games } \\
\text { played on a real trampoline [21]. }\end{array}$ \\
\hline Affect & $\begin{array}{l}\text { Svink's and Bordwell's analyses of action } \\
\text { game and action film aesthetics }[7,44] .\end{array}$ & $\begin{array}{l}\text { Research and examples of thrill rides [3,5, } \\
31] \text { and extreme sports [8]. Caillois and } \\
\text { Kenyon discuss 'vertigo' play, which is } \\
\text { related to gravity and thrill }[9,25] \text {. }\end{array}$ & $\begin{array}{l}\text { Interactive experiences with gravity-induced } \\
\text { thrill }[3,31] \text {. Initial studies of the effects of } \\
\text { mixed-reality gravity manipulation on } \\
\text { affective dimensions [24]. }\end{array}$ \\
\hline Challenge & $\begin{array}{l}\text { Puzzles involving gravity manipulation } \\
\text { (e.g., Rochard [55]), or controlling } \\
\text { physically based simulated game characters } \\
\text { with no automatic balancing (QWOP, } \\
\text { Toribash }[54,56] \text { ) }\end{array}$ & $\begin{array}{l}\text { Gravity limits athletic skills: jumping } \\
\text { height \& length, running speed etc. Gravity } \\
\text { causes a balancing and intellectual puzzle } \\
\text { challenge in non-digital games like Twister } \\
\text { [57], and a multitude of challenges in sports } \\
\text { (emotional, strength, endurance, timing...) }\end{array}$ & $\begin{array}{l}\text { The field of movement-based games is vast, } \\
\text { but not all styles of challenges have been } \\
\text { equally explored. Puzzles and intensive } \\
\text { strength challenges appear underrepresented } \\
\text { with some exceptions (e.g., }[23,36]) \text {. } \\
\text { Sometimes incidental, unintentional } \\
\text { ergonomic challenges/flaws. }\end{array}$ \\
\hline $\begin{array}{l}\text { Movement } \\
\text { diversity }\end{array}$ & $\begin{array}{l}\text { Emergent and unexpected movement in } \\
\text { physically based games such as QWOP. } \\
\text { Recently, also real-time synthesis of } \\
\text { complex, emergent behaviors in robotics } \\
\text { and procedural animation }[16,45] \text {. }\end{array}$ & $\begin{array}{l}\text { Gravity-induced constraints are } \\
\text { manipulated both using gravity-fighting } \\
\text { equipment (trampolines etc.), but also in } \\
\text { various movement arts by varying the } \\
\text { amount and type of support points (hands, } \\
\text { feet) and surface inclinations (floor, wall, } \\
\text { slide). }\end{array}$ & $\begin{array}{l}\text { Largely underexplored. Some recent studies } \\
\text { about interaction in water and on a climbing } \\
\text { wall }[23,30] \text {. No studies of gravity-based } \\
\text { interactions with virtual characters or robots } \\
\text { with complex movement improvisation } \\
\text { abilities. }\end{array}$ \\
\hline Sociality & $\begin{array}{l}\text { Digital co-op games with gravity-based } \\
\text { mechanics, e.g., Little Big Planet, ibb \& } \\
\text { obb }[50,51] .\end{array}$ & $\begin{array}{l}\text { Cheerleading and underwater rugby are } \\
\text { examples of real-world sports where gravity } \\
\text { (or buoyancy, the opposite of gravity) } \\
\text { provides a central challenge for a team. } \\
\text { Twister can also be argued to fall in this } \\
\text { category. }\end{array}$ & $\begin{array}{l}\text { Largely underexplored. Haptic Turk provides } \\
\text { a rare prior example of combined digital and } \\
\text { physical social bodily play with gravity [10]. }\end{array}$ \\
\hline
\end{tabular}

Table 1. Summary of how our facets (left) have been explored in digital, physical, and mixed-reality experiences.

noticed that we had so far explored only fragments of a wider design space of gravity-based interactions, which we attempt to systematically map out in this paper in order to inform future work. The discovery of gravity as a common ingredient in our work has been intriguing and inspiring for us, which we hope to share with the HCI and games community.

The paper is structured around five central gravity-related facets of user experience that we have identified based on our work and that of others: realism, affect, challenge, movement diversity, and sociality. Although there are various previous design frameworks and guidelines for bodily HCI [29, 34, 35], none of them explicitly consider the multifaceted role of gravity. We hope that our framework suggests valuable new ideas for both researchers and practitioners, and provides vocabulary for discussing and thinking about gravity-based experiences.

As summarized in Table 1, the following sections discuss each of the five facets from the point of view of 1) purely digital/virtual applications such as video games played using a gamepad, 2) physical, real-world applications such as technologies for manipulating gravity for rehabilitation after injuries, and 3) combinations of thereof, i.e., mixed- reality experiences spanning both the real and the virtual. This structure reveals that gravity is an underexplored design resource for movement-based games, and the various digital and physical approaches could be combined in novel ways. Examples of such future directions are given at the end of each section.

\section{Methodology}

An initial literature search using keywords "humancomputer interaction", "HCI", "gravity", and "games" revealed that a pure systematic review of the topic is infeasible. It was found that such searches produce too many irrelevant results, such as technical papers related to tracking the center of gravity of the human body. On the other hand, the word 'gravity' is not explicitly used in many relevant papers. Hence, this paper draws heavily on the authors' own experience of designing and evaluating several related interactions, and observing hundreds of users in both controlled studies and at various events.

Our work is inspired by and draws on various previous bodily interaction frameworks. For example, our facet of realism is somewhat analogous to the 'technological' of Segura et al. [29], while our affect, challenge, and diversity all relate to their 'physical'. On the other hand, our 
discussion of realism, challenge, and diversity could be considered to increase the resolution of the lens of the 'moving body' of Mueller et al. [34], while our facet of affect relates to both their 'responding body' and 'sensing body'. Gravity could be also considered an additional parameter or a modulator of the parameters in Fogtmann et al. [14]. Moen [33] points out that movement arts can work with gravity and/or against it; we elaborate on how this can be achieved with different technologies and design approaches.

Overall, we have not found a previous framework where all the elements would be relevant to gravity; we thus provide our own set of facets to complement previous frameworks, in an attempt to compress the most relevant material to fit a single paper.

\section{FACET 1: REALISM}

This facet refers to how gravity can create or impair realism, and how perceived gravity can be manipulated to create fantasy experiences beyond realism.

Action games like Spacewar simulate gravity to create some degree of realism. In contrast, gravity often appears to be the missing piece of realism in movement-based games the player's avatar is often flying in the air or floating in simulated water, but HCI in such real-world environments is only beginning to be examined [30,32].

In commercial movement-based games, the player is still typically standing in front of a screen. In this case, the need to have a solid base of support limits the movements, e.g., one cannot freely rotate except around the vertical axis. Hämäläinen and Höysniemi [17] provide an example of the effect of such real-virtual conflict: In their physically interactive children's game, the flying avatar was controlled by standing in front of a camera, waving hands and bending the torso. As there was no clear mapping from the player's feet to the flying avatar, the user study participants were observed to accidentally take steps and occasionally even drift outside the camera's view. Standing in front of a camera to fly or swim is obviously a practical compromise - more realistic simulations have been developed, but are hardly yet feasible for mass production (e.g., [13]).

The fields of virtual reality and simulators provide various examples of enhancing realism and (partially) emulating gravity in the real world, e.g., using an actuated cockpit in a flight simulator. The Augmented Thrill Ride is a recent example that uses a real rollercoaster to simulate, e.g., the g-forces of a virtual reality space fight [3].

Considering intentional non-realism, mankind has a long history of developing gravity-fighting, empowering technologies such as trampolines, antigravity harnesses, wire-flying, exoskeletons, and zero-gravity parabolic flights. These have been used for movement rehabilitation,

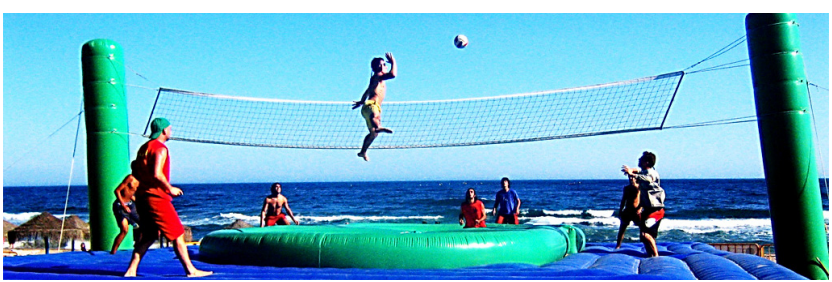

Figure 2. Bossaball combines volleyball and trampolines.

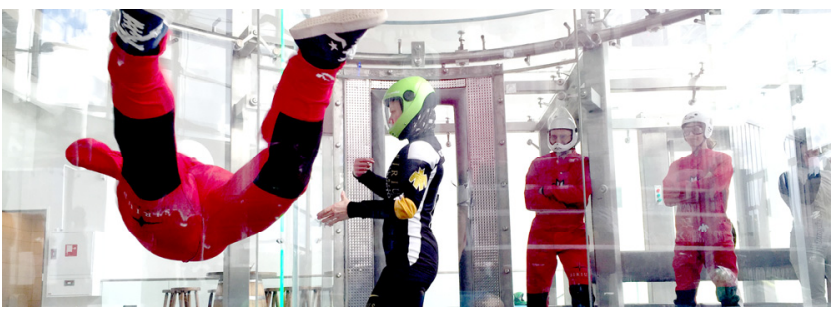

Figure 3. The authors (in red suits) in a vertical wind tunnel, a potential environment for digital augmentation.

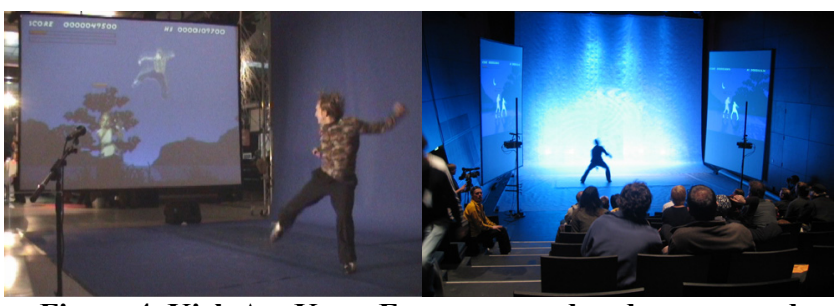

Figure 4. Kick Ass Kung-Fu empowered and encouraged movement using exaggerated simulated physics and a large cushioned playfield with dual projected screens [18].
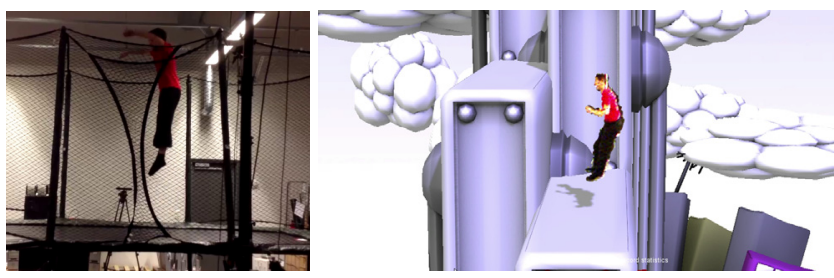

Figure 5. Exaggerating jumping height in a Kinect game using a real trampoline [21]

scaffolding motor learning ${ }^{2}$, astronaut training, circus and movie stunts, as well as designing empowering and thrilling new sports and activities like Bossa ball (volleyball with trampolines embedded in the playing field, Figure 2), Slamball (basketball with trampolines), and indoor skydiving (Figure 3). On the other hand, exaggerated simulated physics - the digital equivalent of trampolines and wind tunnels - has been a staple of digital games since early platformers like Mario Bros [52].

\section{Future directions considering realism}

In bodily HCI, the full-body fighting game Kick Ass Kung$\mathrm{Fu}$ [18] empowered the players by boosting their on-screen running speed and jumping height, as shown in Figure 4. A logical future direction is to combine both physical and digital gravity and movement manipulation, an approach

\footnotetext{
${ }^{2}$ For example, a trampoline increases air time, making it easier to practice aerial skills for floor gymnastics.
} 
dubbed mixed reality empowerment in conjunction with Kinect games played on a real trampoline [19, 21, 24]. So far, the possibilities of mixed reality empowerment are largely underexplored. For example, there are various mechanical systems that attempt to simulate realistic locomotion in virtual reality (e.g., [22]), but there appears to be no such systems for exaggerated, superhuman locomotion, although such systems could possibly be implemented utilizing support structures and harnesses similar to bungee trampolines. There are also no reports about digitally augmented interactive indoor skydiving or zero-gravity exergames for astronauts and space tourism.

Contemporary circus such as Cirque du Soleil's Kà integrates both interactive graphics and gravity-fighting real-world equipment [11]. One could consider such circus performer's experience - mid-air martial arts and acrobatics in a digitally enhanced environment - as the logical extreme of mixed reality empowerment; however, the performers also represent the extreme of human physical capability, and the democratization of such experiences for the average player remains a challenge. In practice, aerial harnesses may cause heavy discomfort, especially for novice performers. Loke and Khut [27] provide a recent practical example of combining circus equipment (cloth suspension) with HCI input devices (a Wii balance board) in interactive art.

\section{FACET 2: AFFECT}

This facet considers the affective, emotional, and aesthetic experience of gravity.

Gravity is a dominant source of risk in many sports, and induces fear of falling, but as noted by various authors, with risk comes the sense of thrill $[5,35]$. Surviving a thrill ride can induce a sense of euphoric relief [5], and experiencing motor mastery in gravity-defying sports like parkour can be empowering. According to Breton [8], the perceived risk of pain or death from falling is key to the experience of many extreme sports. Related to thrill is Caillois' definition of 'vertigo' play that consist of "an attempt to momentarily destroy the stability of perception and inflict a kind of voluptuous panic upon an otherwise lucid mind", e.g., a child spinning until they fall down [9]. Building on Caillois, Kenyon [25] discusses the pursuit of vertigo as physical experiences providing thrill through speed, acceleration, sudden change of direction, or exposure to risk. Kenyon also notes how people pursue vertigo, but don't necessarily achieve it, which we see as a potential area for technology to assist.

In digital games and other mediated movement experiences - sports broadcasts, action films - the users/spectators may not be participating actively with their bodies, but the affective and aesthetic qualities of movement are still essential. Bordwell [7] argues how Sergei Eisenstein, a pioneer of early $20^{\text {th }}$ century cinema, already searched for expressive movement that the spectators would feel in their bodies, and how gravity-defying movement is central to the aesthetics of Hong-Kong action films. Svink [44] suggests that organic, curved motion such as that induced by gravity is found pleasurable in action games.

\section{Future directions considering affect}

In bodily HCI, gravity-induced thrill has been deliberately utilized in interactive amusement rides such as the Broncomatic [31]. Broncomatic is a modified 'rodeo bull' amusement ride, converted into a breath sensing computer game. It senses a rider's breathing, and maps it onto the movement of the ride, whilst the rider has to try and stay on top for as long as possible. Gravity is key to the generation of thrill in Broncomatic in that the end-condition of the game is to be thrown entirely off the ride.

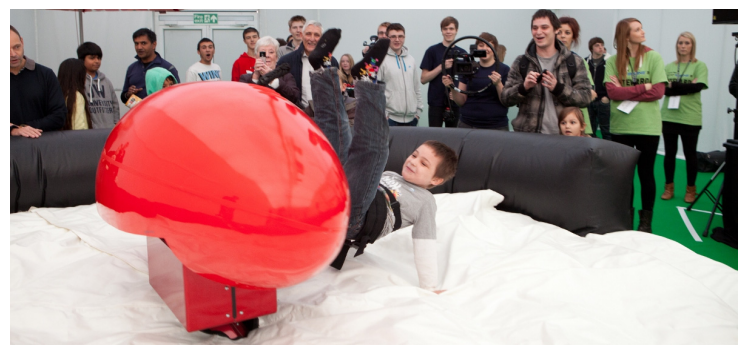

Figure 6. The Broncomatic [31]

An interesting underexplored question appears to be how real and/or virtual gravity manipulation affects the user experience, e.g., whether one can increase the perceived risk and thrill without causing an actual elevated physical risk. There are some results indicating that this might be possible. Kajastila et al. [19] found that on-screen exaggeration of jumps increased players' arousal. Some of their trampoline experiments also combine the thrill and bodily sensations of high jumps with virtual on-screen obstacles, which reduce risk compared to adding real obstacles on a trampoline [21].

\section{FACET 3: CHALLENGE}

This facet refers to how gravity can create both meaningful and incidental challenges for movement.

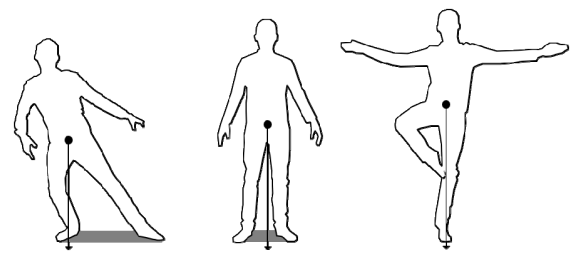

Figure 7. The basic principle of balancing is that a line drawn from the center of mass (roughly at the hips) in the direction of gravity must intersect the support area (gray) defined by contacts with the supporting surface.

One of the most obvious roles of gravity is that it creates challenges for movement. Gravity limits how high we can jump, how we can balance (Figure 7), and also how fast we can run, as gravity both causes friction and requires that a portion of expended energy is used in the vertical direction instead of increasing horizontal speed. Gravity-related 
challenges can be further divided into intellectual (e.g., selecting the correct sequence of climbing holds), emotional (overcoming fear), strength, endurance, coordination, balance, and timing (e.g., in aerial acrobatics).

Many texts on game design highlight the importance of constructing meaningful challenges $[12,37,39]$. We argue that the same applies to gravity: The intellectual challenge of selecting the correct climbing strategy attracts climbers, but on the other hand, many movement-based games include gravity-related challenges that are less meaningful given the game context. In the Michael Phelps Kinect swimming game [53], players emulate swimming in an upright posture where gravity causes a strain to shoulder muscles, in stark contrast to actual swimming where one is supported by water. Mueller's and Isbister's movementbased game guidelines state that fatigue as a game challenge should be intentional rather than incidental [35]; in the Michael Phelps swimming game, some fatigue was probably intended but the exact muscles strained due to gravity may be incidental.

We consider Hanging off a Bar [36] (Figure 8) as a positive example of utilizing gravity to create an intentional, meaningful challenge: the player hangs off a chin-up bar to get over virtual obstacles projected on the ground. The required struggle against gravity is clearly communicated and hanging performance is directly mapped to how far the player gets in the game. Furthermore, being able to hang for a long time has benefits outside the game in, e.g., climbing.

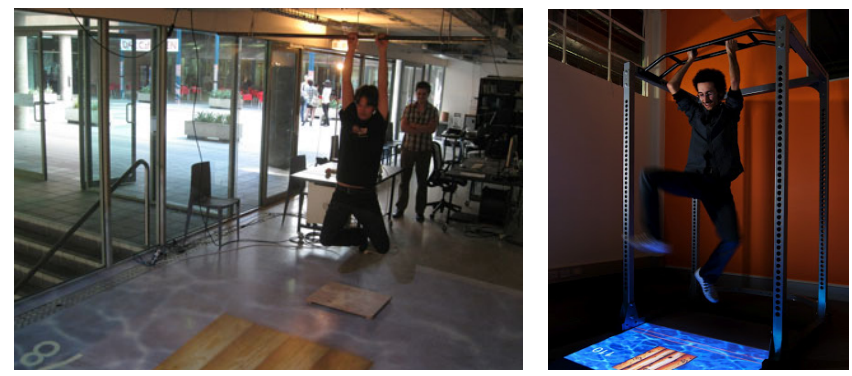

Figure 8. Hanging off a Bar [36].

\section{Gravity-related challenges in purely digital games}

Various purely digital games implement challenges where the direction and magnitude of gravity are manipulated (e.g, $[48,55])$. Pertaining to the complexity of the human body is the phenomenon of 'awkward physics' games, where the player's task is to directly control parts of a character with simulated physics, often struggling with balancing (e.g., $[54,56])$. For example, in QWOP [54], one is in direct control of the knee and hip joints of a $2 \mathrm{~d}$ human runner, but learning the correct rhythm and choreography of keystrokes is so difficult that one easily ends up falling or even running backwards. The comical, emergent movement gained the game considerable international attention and popularity.

To understand the challenge in QWOP, one should consider how human movement is to large extent possible due to automation achieved through extensive training and repetition [40]. This means that, e.g., in simultaneous walking and interacting with a mobile device, we do not have to consciously pay attention to the exact muscle activations and trajectories of our legs, although learning a stable and efficient walking gait is initially a complex task. Having a basis of automated skills (motor programs) also facilitates learning new skills. However, when the control method is drastically different, e.g., when using a keyboard to play QWOP, our existing automation is of no help. A further complication is that a QWOP player gets feedback only through sound and visuals, whereas real locomotion skills also rely on other feedback modalities which are processed faster, e.g., tactile and proprioceptive feedback causing reflexive, subconscious corrections [40].

\section{Future directions considering challenge}

More natural bodily controls for awkward physics games could be a potential topic for future work. One could, e.g., lie down on the floor on one's back to control all the four legs of a simulated cheetah, which could combine emergent movement and a coordination challenge with a useful strength and endurance challenge for core muscles, similar to the common exercise for abdominal muscles where one pretends to be bicycling.

We also note that recent research provides tools for predicting and quantifying the ergonomics and muscle strain of gestures $[4,20]$. The tools could possibly be used to analyze and optimize the gravity-related challenges for movement-based games.

\section{FACET 4: MOVEMENT DIVERSITY}

This facet refers to how gravity-induced challenges and complexity can promote movement diversity.

Being bound by gravity constrains movements such as balancing, as illustrated in Figure 7 . We argue that altering the constraints, e.g., by changing the orientation or material properties of the support surface, is an effective way of creating meaningful complexity and diversity of movement. Diversity is valuable, as players find creative variation of movement interesting and enjoyable [35]. The same applies to movement professionals as well. As dancer and choreographer Steve Paxton puts it, "I have a hunger to find, and to finish, and to explore, to do essentially what babies do when they begin to move. A hunger to find out more of what movement is or can be." [2].

\section{Gravity and diversity in real sports and games}

Wall climbing provides an excellent example of how using a wall instead of a floor as the support surface introduces complexity and diversity in the form of a new axis of rotation, as illustrated in Figure 9. Most adults are accustomed to upright balancing on a horizontal surface. In such balancing, gravity causes torques only around axes in the support plane $(x, z)$. In climbing, the support area is more complex, defined by both hand and foot holds, and gravity can also twist the player around the $y$ axis. According to the authors' experience, this is not intuitive 
for beginners, and adds an interesting intellectual challenge (figuring out the correct strategy), as well as a movement challenge, as executing a strategy often requires high degree of strength, coordination and accuracy.

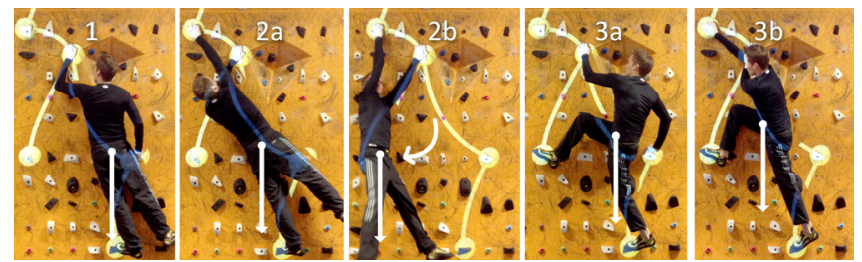

Figure 9. An example of a correct climbing sequence $(1,3 \mathrm{a}, 3 \mathrm{~b})$ and an incorrect one $(1,2 a, 2 b)$, which causes the player to swing around the vertical axis (a barn-door effect).



Figure 10. Bounden is a two-player game where movement is constrained and choreographed by a mobile device [49]. Image courtesy of Game Oven.

In addition to changing the environment, gravity-related movement constraints can be altered by supporting the body using body parts other than feet. This is explored especially in various bodyweight-only movement training regimes and styles (e.g., [46]). For example, there are over a dozen variations of the push-up, each training slightly different muscles by varying the angle of the body and the placement of the support points. Balancing and moving on both hands and feet is also common in many dance styles, e.g., contemporary and breakdance.

The classic non-digital game Twister [57] provides a great example of a gravity challenge with interesting complexity emerging from simple rules that modify the supporting limbs. In the game, one or more players move on a mat with colored circles, and one player gives commands defining which limbs should touch which color.

\section{Gravity and diversity in digital and mixed reality games}

Considering digital games, physics-based puzzles like Angry Birds utilize simulated physics and gravity to create diverse emergent behavior from simple interactions; little changes in projectile launch parameters can cause large variations in how a simulated fortification breaks. In the QWOP game introduced in previous section, diversity and complexity of simulated humanoid movement is used for a comic effect (e.g., [43]) - complexity and emergent movement lead to infinite variations of hitting one's head on the ground.

In movement-based video games, movement constraints can be altered in both real and virtual environments. The augmented climbing wall by Kajastila and Hämäläinen provides an example of full-body interaction on a vertical surface [23]. Another example of complexity and diversity through movement constraints is Bounden (Figure 10), a mobile dance game where two players hold on to the same mobile phone and try to move the phone as instructed, while avoiding getting tangled and losing balance [49]. Kick Ass Kung-Fu also considered gravity in the physical design, utilizing a large cushioned playfield to soften landings from jumps and encourage the exploration of movements such as flips and ukemi rolls that are more risky on a hard floor [18].

\section{Future directions considering movement diversity}

It appears that the diversity of body movement is still underexplored in movement-based games. Non-standing movement and interactions, e.g., kneeling or touching the ground with a hand is rare in dancing games, in contrast to many real dance styles. The Kinect version of Twister [58] abandons the original Twister's complexity and threedimensionality for $2 \mathrm{~d}$ standing gameplay where the player matches silhouette shapes and avoids obstacles. This is probably due to 1) the need for a mass market game to not be too exhausting and physically demanding, 2) off-theshelf trackers like the Kinect having difficulty tracking unusual body positions, possibly due to the fact that the tracking is based on large amounts of machine learning training data [42], which is apparently mostly gathered from standing and seated users, and 3) games being predominantly visual, requiring the player to be able to see a screen. In the future, there may be interesting possibilities in, e.g., combining floor displays with floor multitouch sensing and body tracking, or exploring movement diversity without displays, as in i-dentity, a multiplayer game using the glowing orb of the PlayStation Move controller as the feedback channel [15]. There probably is also unexplored movement diversity in different physical gravity environments, such as varying surface inclinations or water.

One may question whether the physically based emergent movement of QWOP could be combined with less extreme difficulty, e.g., by giving higher level commands to an artificial intelligence that drives the simulated character. However, it turns out that optimizing virtual muscle activations for simulated humanoids based on movement goals and constraints is a hard problem in robotics and procedural animation with no robust, general, and real-time solution. There has been considerable success only in the past few years $[16,45]$, which explains why most digital games, e.g., spatial puzzles, derive complexity from adding manipulated objects, instead of utilizing the inherent complexity of the moving body as in climbing and QWOP. Most game characters are presently implemented by displaying and blending a predefined set of animations, which limits the diversity of interactions.

The technological limitations above are probably one reason why bodily interaction with virtual characters has been particularly limited. Although technologies like Kinect enable software to sense and interpret complex body 


\begin{tabular}{|c|c|c|c|c|c|}
\hline & Realism & Affect & Challenge & Diversity & Sociality \\
\hline Realism & $\begin{array}{l}\text { Could and should you } \\
\text { manipulate gravity, e.g., } \\
\text { using circus and sports } \\
\text { equipment or exaggerated } \\
\text { simulated physics? } \\
\text { If gravity affects realism, } \\
\text { e.g., through differences } \\
\text { in the real and virtual } \\
\text { environments, is the effect } \\
\text { intended? }\end{array}$ & $\begin{array}{l}\text { Can manipulating } \\
\text { realism result in } \\
\text { positive affect } \\
\text { (empowerment, } \\
\text { thrill)? }\end{array}$ & $\begin{array}{l}\text { Can manipulating } \\
\text { realism optimize } \\
\text { challenge? What are } \\
\text { the real and virtual } \\
\text { challenges? }\end{array}$ & $\begin{array}{l}\text { Does manipulating realism lead to } \\
\text { increased or decreased diversity? } \\
\text { E.g., does the experience empower } \\
\text { the user to explore new movements? }\end{array}$ & $\begin{array}{l}\text { Does the realism } \\
\text { manipulation work for one } \\
\text { or multiple players? How do } \\
\text { other people perceive it, e.g., } \\
\text { is the empowerment or thrill } \\
\text { mediated? }\end{array}$ \\
\hline Affect & & $\begin{array}{l}\text { Does gravity } \\
\text { cause positive or } \\
\text { negative } \\
\text { emotions, e.g., } \\
\text { fear, } \\
\text { empowerment? } \\
\text { Why? }\end{array}$ & $\begin{array}{l}\text { Do the challenges } \\
\text { promote positive } \\
\text { affect as in, e.g., } \\
\text { climbing, where thrill } \\
\text { and sense of mastery } \\
\text { grows as the climber } \\
\text { gets higher? }\end{array}$ & $\begin{array}{l}\text { Does the experience promote the joy } \\
\text { of discovery of new movements? }\end{array}$ & $\begin{array}{l}\text { Are people able to contribute } \\
\text { to each other's affect and } \\
\text { emotions? Climbers, for } \\
\text { example, spot and cheer each } \\
\text { other (while one climbs and } \\
\text { others spectate), helping one } \\
\text { to conquer fear and gravity. }\end{array}$ \\
\hline Challenge & & & $\begin{array}{l}\text { Does gravity present } \\
\text { meaningful challenge? } \\
\text { Can you create } \\
\text { interesting puzzles } \\
\text { using the body only as } \\
\text { in climbing, or do you } \\
\text { need manipulated real } \\
\text { or virtual objects? }\end{array}$ & $\begin{array}{l}\text { Are there challenges promoting } \\
\text { movement diversity, e.g., a reward } \\
\text { for coming up with a new climbing } \\
\text { strategy? }\end{array}$ & $\begin{array}{l}\text { Are gravity-related } \\
\text { challenges individual (e.g., } \\
\text { running) or social (e.g., } \\
\text { building a human pyramid)? } \\
\text { Could and should you } \\
\text { include both components? }\end{array}$ \\
\hline Diversity & & & & $\begin{array}{l}\text { Could and should you manipulate } \\
\text { gravity-related movement } \\
\text { constraints, e.g., using surfaces of } \\
\text { different inclinations or using } \\
\text { different body parts for balancing? } \\
\text { If the user is e.g., lying on the floor, } \\
\text { what display technology works best } \\
\text { (e.g., a ceiling display or a HMD)? }\end{array}$ & $\begin{array}{l}\text { Can people contribute to } \\
\text { each other's movement } \\
\text { exploration and discovery, } \\
\text { e.g., by designing and } \\
\text { sharing experiences for each } \\
\text { other? }\end{array}$ \\
\hline Sociality & & & & & $\begin{array}{l}\text { What collaborative or } \\
\text { competitive interactions does } \\
\text { gravity enable or prevent? }\end{array}$ \\
\hline
\end{tabular}

Table 2. The framework facets and their combinations as lenses, i.e., sets of questions to inform design and research.

language, virtual characters have lacked similarly complex movement capabilities of their own. Therefore, we find the recent technological advances in robotics and procedural animation fascinating, and predict new future possibilities for bodily $\mathrm{HCI}$, e.g., interactions like Bounden but with virtual characters capable of diverse, emergent movement.

\section{FACET 5: SOCIALITY}

This facet refers to the social experiences enabled and/or prevented by gravity.

There are various purely physical activities where people co-operate against gravity, e.g., creating a human pyramid, throwing and catching aerial acrobats in cheerleading, or a circus act where two persons help each other gain momentum and height on a teeterboard. In underwater rugby, teams compete both against each other and buoyancy, i.e., the opposite of gravity. Gravity is also key to the spectator experience of many sports due to the appeal of watching people fight against gravity and the risks that entails. This appeal is perhaps epitomized in the massively popular collections of skateboard 'fail' videos consisting entirely of people falling to the ground whilst attempting tricks.

Considering digital games, ibb \& obb [50] and Little Big Planet [51] are examples of co-operative games with gravity-based game mechanics. In ibb \& obb, gravity goes both up and down, and the game encourages collaboration by letting characters push and bounce off each other to fight gravity. Little Big Planet features various physics-based puzzles such as building structures to get over obstacles.

\section{Future directions considering sociality}

Gravity-based social play seems surprisingly uncommon and underexplored in bodily HCI, although many authors highlight the importance of the social aspects of embodied interaction $[29,34]$. A rare and recent exception is Haptic Turk [10], where a primary player experiences an immersive hang glider experience with a head-mounted display device. Other players collaboratively fight gravity 
by lifting, tilting and pushing the primary player according to the game's instructions.

\section{THE FACETS AS LENSES}

The above exploration of the facets prompts various questions, which we have gathered in Table 2 to help understanding and designing gravity-based interactions. The table systematically considers not only each facet, but all the facet pairs. This is motivated by research suggesting that finding the right questions to ask is key to scientific discovery and creative process $[28,38]$. The cells of the table can also be considered conceptual lenses extending those of, e.g., Schell [39]. Together, tables 1 and 2 form a framework that can be used analyze designs and synthesize new ideas. One can, e.g., select one of the proposed future directions as a starting point, and then inform and refine ideas using the questions of Table 2. The following applies the framework to two projects.

\section{DESIGN EXAMPLE: THE BODYFLIP GAME}

In this section we demonstrate the use of our framework in creating and evaluating a novel movement-based game called BodyFlip. The game uses a smartphone strapped to the player's torso to give audio instructions to point a part of one's body downwards (head, feet, left side, right side, front, back), or to tap or shake the device. The players get ten instructions per level, followed by a rest period. If they fail to move fast enough the game ends. Because BodyFlip senses device orientation rather than specific actions, there are many ways to follow each instruction.

BodyFlip explores the proposed future direction of nonstanding movement. It aims to create movement diversity (Facet 4: Diversity) whilst being playable using a range of different gravity manipulation technologies (Facet 1: Realism). It deliberately uses movements in all $3 \mathrm{~d}$ directions, aiming to create an interesting gravity challenge (Facet 3 ) in a range of environments.

In an initial study, 6 players tested BodyFlip in three conditions: hard floor (HF), padded gym mat (PM), and hanging from gymnastics rings (GR). Each player experienced the three conditions in different order and played three levels per condition. After each condition, the participants were asked to rate the game for difficulty and fun, and give reasons for the ratings. After all three conditions, participants rated the conditions in relation to each other, and described how playing felt different in each condition. The difficulty and fun ratings are not statistically reliable given the limited sample, but they prompted some of the user comments included below.

We also tested BodyFlip in a swimming pool using a waterproof belt case and headphones. Unfortunately our case broke and the test phone was damaged during testing, leaving data from only one swimmer. The following presents our findings based on the total of $6+1$ participants, considering the most relevant framework facets.
Facet 4: Diversity. Different play conditions had strong effects on how players moved. All players preferred PM to $\mathrm{HF}$, saying that they felt able to perform a wider range of movements, such as jumping onto their back because of the "comfortable danger-free feeling" floor which enabled more flowing movements "It is fun to do summersaults and continue the movement, try to get the movements flowing “. With rings the constraint of having to keep hanging meant that people used completely different movements (Figure 11). Constant bodily support of water led to a less diverse range of actions for the swimmer, who simply rolled in the direction requested.
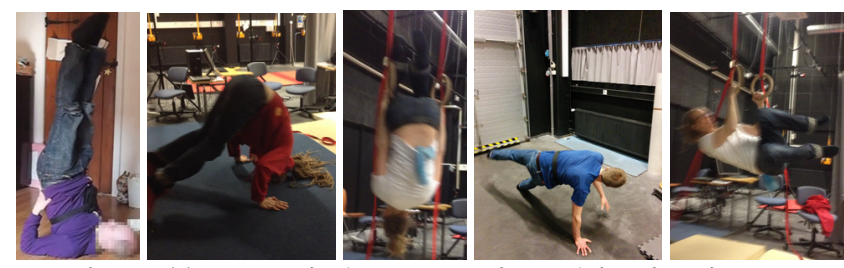

Figure 11. BodyFlip 'head down' and 'right' actions on ground and rings

Facet 3: Challenge. Both the hard floor and the rings made movements more difficult. With rings this provides a meaningful intellectual and strength challenge ("it's an interesting challenge", "I had to think a lot more, and it was at the same time pretty heavy."), whereas players did not like the hard floor which they felt limited them to slow and cautious play without adding an interesting challenge. The water in the pool made movements far less difficult; in this case the swimming participant felt that it reduced the physical and mental challenges too much.

Facet 2: Affect. The padded mats were largely viewed positively as promoting more playful experiences. ("childlike joy of movement because of the soft floor", "playful, amusing, childlike feeling", "fun to goof around on the soft floor")

In summary, our key findings are 1) given the exact same game, different environments support different types of play, such as a struggle to meet goals (GR) and playful exploration (PM), and 2) the environment's movement constraints can either inhibit playful exploration (HF), or provide a meaningful intellectual and physical challenge (GR). The HF condition was ranked inferior to PM and GR by all participants.

\section{ANALYTICAL EXAMPLE: AUGMENTED CLIMBING}

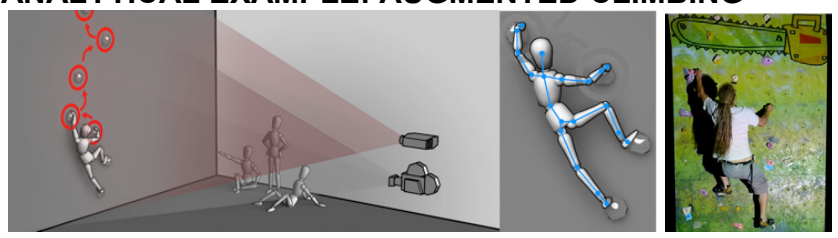

Figure 12. The augmented climbing wall [23]

Our framework can also be used to analyze and suggest improvements to an existing project, in this case the augmented climbing wall (ACW) by Kajastila and 
Hämäläinen [23]. As shown in Figure 12, ACW allows the climber to interact with projected graphics such as a route to climb or an animated object to evade. ACW is designed for bouldering, i.e., climbing on a low wall with thick matrasses for safety instead of ropes. The following analysis is based on both the ACW study [23] and student feedback from a game design course where the students experienced different movement activities to better understand their representations in games. The students did non-augmented bouldering on one day and also tried an $\mathrm{ACW}$ setup on the last day of the course. Below, quotes from the students are marked "STU". In total there were 8 original ACW study participants and 9 students.

Facet 1: Realism. No gravity manipulation was employed in the augmented climbing wall.

Facet 2: Affect. The gravity-induced affect, physicality and fear in climbing is evident in the student feedback: "To be in the limits of your physical abilities and the aspect of danger was a really powerful experience. The energetic effect lasted two days after bouldering" (STU).

Facet 3: Challenge. The game design students were intrigued by the gravity-based puzzle-solving aspects: "[In climbing 7 you need lot of problem solving skills, planning, and understanding the forces" (STU). It was also considered interesting that one's limited strength induces a natural time limit: "I was involved making different decisions in a short time in order to avoid falling and losing the power/strength left in the body. All the joints and even the knuckles were involved", "It was also a great puzzle type - one with possibly different solutions and time pressure built into it physically" (STU).

Facet 4: Diversity. As explained earlier, moving on a vertical surface requires movements and skills highly different from floor-based activities. The augmented climbing wall further promotes diversity with two approaches: 1) An automatic route generator forces the climber to do unexpected moves and forces a climber out of the comfort zone: "The unexpected moves makes it a good training method". 2) In another prototype, a second climber used a mouse to define handholds for the climber on the wall. This also forces the climber to do unexpected moves, and the controller can try to design movement variations that are suitable for the climber's skill level: "Fun and interesting to see how the climber performs the moves I designate to him".

Facet 5: Sociality. Bouldering is a social experience, where people solve puzzles together, share ideas, and spectators cheer the climbers to help them overcome gravity and fear. The augmented climbing wall seeks to enhance this, allowing people to create and share their own routes (the equivalent of game levels).

\section{Extensions and critique suggested by the framework}

- Manipulation of gravity and empowering movement (e.g., dynamic jumps) using elastic ropes and moving/tilting walls (realism, affect)

- Rich $3 \mathrm{~d}$ shapes should be used instead of a flat $2 \mathrm{~d}$ wall, although this complicates computer vision and projections (diversity)

- Projecting a view down from a mountain, an empty void or a pool full of sharks on the floor below the climber (realism, affect)

- Adding holds that can be used only with left or right hand, or holds that "fall" away if used too long (challenge, diversity)

- Gravity makes it risky to have multiple climbers on the same wall. Collaborative/competitive play could be enabled by projecting the image of another climber (sociality)

\section{CONCLUSION}

We have presented a novel five-faceted conceptual framework for understanding gravity as a design resource in movement-based games, summarized in Tables 1 and 2 . Through applying our framework to two example cases, we have demonstrated the potential of our framework as both an analytical and exploratory design tool for investigating the design space of gravity-based interactions and play.

We do not argue that gravity has not played a role in HCI ergonomics in particular - but we believe the various sports, games, and technologies touched upon in this paper highlight the extensive potential gravity offers for novel and engaging HCI experiences. For example, we envision the exploration of movement diversity through different movement constraints - surface inclinations, balancing styles, suspension rigs - as especially promising. Creating challenges and diversity using procedurally animated virtual characters appears as another promising track. Our analysis also prompts new topics for user experience research, e.g., how digital and real movement manipulation affects the thrill and risk experienced by a user and/or an audience.

An obvious limitation of our work is that we have had to simplify the framework and leave out possible (sub)facets. For example, our treatment of affect and emotion focused on empowerment and thrill, and could be augmented with a chapter on physical humor, which was only hinted at when discussing challenge and diversity in awkward physics games.

\section{ACKNOWLEDGMENTS}

We thank the anonymous reviewers and user study participants for their valuable feedback. Joe Marshall is funded by the Leverhulme Trust (ECF/2012-677). Figure 2 by Pedroromero2 (Wikimedia Commons, CC BY-SA 3.0). 


\section{REFERENCES}

1. 10 most important video games of all time, as judged by 2 designers, 2 academics, and 1 lowly blogger. http://www.joystiq.com/2007/03/12/10-mostimportant-video-games-of-all-time-as-judged-by-2design/. Accessed: 2014-09-11.

2. About reasons to be a mover. 2012. http://vimeo.com/ 48276698. Accessed: 2014-09-17.

3. Augmented Thrill Ride Project. 2014. http://www.vrcoaster.com/. Accessed: 2014-09-15.

4. Bachynskyi, M., Oulasvirta, A., Palmas, G. and Weinkauf, T. 2013. Biomechanical Simulation in the Analysis of Aimed Movements. CHI '13 Extended Abstracts on Human Factors in Computing Systems (New York, NY, USA, 2013), 277-282.

5. Benford, S., Greenhalgh, C., Giannachi, G., Walker, B., Marshall, J. and Rodden, T. 2012. Uncomfortable Interactions. Proceedings of the SIGCHI Conference on Human Factors in Computing Systems (New York, NY, USA, 2012), 2005-2014.

6. Bianchi-Berthouze, N. 2013. Understanding the Role of Body Movement in Player Engagement. HumanComputer Interaction. 28, 1 (2013), 40-75.

7. Bordwell, D. 2001. Aesthetics in Action: Kungfu, Gunplay, and Cinematic Expressivity. In Esther Yau, ed. At full speed: Hong Kong cinema in a borderless world. (2001), 73-93.

8. Breton, D.L. 2000. Playing Symbolically with Death in Extreme Sports. Body \& Society. 6, 1 (Mar. 2000), 111.

9. Caillois, R. 1961. Man, Play and Games. The Free Press.

10. Cheng, L.-P., Lühne, P., Lopes, P., Sterz, C. and Baudisch, P. 2014. Haptic Turk: A Motion Platform Based on People. Proceedings of the SIGCHI Conference on Human Factors in Computing Systems (New York, NY, USA, 2014), 3463-3472.

11. Cirque du Soleil Kà. http://www.cirquedusoleil.com/ en/home.aspx\#/en/home/shows/details/ka.aspx.

12. Costikyan, G. 2005. I Have No Words \& I Must Design. The game design reader: A rules of play anthology. (2005).

13. Fels, S., Yohanan, S., Takahashi, S., Kinoshita, Y., Funahashi, K., Takama, Y. and Chen, G.T.-P. 2005. User Experiences with a Virtual Swimming Interface Exhibit. Entertainment Computing - ICEC 2005. F. Kishino, Y. Kitamura, H. Kato, and N. Nagata, eds. Springer Berlin Heidelberg. 433-444.

14. Fogtmann, M.H., Fritsch, J. and Kortbek, K.J. 2008. Kinesthetic Interaction: Revealing the Bodily Potential in Interaction Design. Proceedings of the 20th Australasian Conference on Computer-Human Interaction: Designing for Habitus and Habitat (New York, NY, USA, 2008), 89-96.

15. Garner, J., Wood, G., Pijnappel, S., Murer, M. and Mueller, F. 2014. I-dentity: Innominate Movement Representation As Engaging Game Element.
Proceedings of the 32Nd Annual ACM Conference on Human Factors in Computing Systems (New York, NY, USA, 2014), 2181-2190.

16. Hämäläinen, P., Eriksson, S., Tanskanen, E., Kyrki, V. and Lehtinen, J. 2014. Online Motion Synthesis Using Sequential Monte Carlo. ACM Trans. Graph.. 33, 4 (Jul. 2014), 51:1-51:12.

17. Hämäläinen, P. and Höysniemi, J. 2003. A Computer Vision and Hearing Based User Interface for a Computer Game for Children. Universal Access Theoretical Perspectives, Practice, and Experience. N. Carbonell and C. Stephanidis, eds. Springer Berlin Heidelberg. 299-318.

18. Hämäläinen, P., Ilmonen, T., Höysniemi, J., Lindholm, M. and Nykänen, A. 2005. Martial arts in artificial reality. Proceedings of the SIGCHI conference on Human factors in computing systems (2005), 781-790.

19. Hämäläinen, P. and Kajastila, R. 2014. Mixed reality empowerment for enhancing physical exercise. CHI'14 HCI in Sport Workshop (2014).

20. Hincapié-Ramos, J.D., Guo, X., Moghadasian, P. and Irani, P. 2014. Consumed Endurance: A Metric to Quantify Arm Fatigue of Mid-air Interactions. Proceedings of the SIGCHI Conference on Human Factors in Computing Systems (New York, NY, USA, 2014), 1063-1072.

21. Holsti, L., Takala, T., Martikainen, A., Kajastila, R. and Hämäläinen, P. 2013. Body-controlled trampoline training games based on computer vision. CHI '13 Extended Abstracts on Human Factors in Computing Systems (New York, NY, USA, 2013), 1143-1148.

22. Iwata, H. and Fujii, T. 1996. Virtual perambulator: a novel interface device for locomotion in virtual environment. Virtual Reality Annual International Symposium, 1996., Proceedings of the IEEE 1996 (Mar. 1996), 60-65, 265.

23. Kajastila, R. and Hämäläinen, P. 2014. Augmented Climbing: Interacting With Projected Graphics on a Climbing Wall. CHI '14 Extended Abstracts on Human Factors in Computing Systems (2014).

24. Kajastila, R., Holsti, L. and Hämäläinen, P. 2014. Empowering the Exercise: a Body-Controlled Trampoline Training Game. Int. J. of Computer Science in Sport. 13, 1 (2014).

25. Kenyon, G.S. 1968. A Conceptual Model for Characterizing Physical Activity. Research Quarterly. American Association for Health, Physical Education and Recreation. 39, 1 (Mar. 1968), 96-105.

26. Krueger, M.W., Gionfriddo, T. and Hinrichsen, K. 1985. VIDEOPLACE - an artificial reality. Proceedings of the SIGCHI Conference on Human Factors in Computing Systems (New York, NY, USA, 1985), 35-40.

27. Loke, L. and Khut, G.P. 2011. Surging Verticality: An Experience of Balance. Proceedings of the Fifth International Conference on Tangible, Embedded, and 
Embodied Interaction (New York, NY, USA, 2011), 237-240.

28. Lubart, T.I. 2001. Models of the Creative Process: Past, Present and Future. Creativity Research Journal. 13, 3-4 (Oct. 2001), 295-308.

29. Márquez Segura, E., Waern, A., Moen, J. and Johansson, C. 2013. The design space of body games: technological, physical, and social design. Proceedings of the SIGCHI Conference on Human Factors in Computing Systems (New York, NY, USA, 2013), 3365-3374.

30. Marshall, J. 2013. Smartphone Sensing for Distributed Swim Stroke Coaching and Research. Proceedings of the 2013 ACM Conference on Pervasive and Ubiquitous Computing Adjunct Publication (New York, NY, USA, 2013), 1413-1416.

31. Marshall, J., Rowland, D., Rennick Egglestone, S., Benford, S., Walker, B. and McAuley, D. 2011. Breath Control of Amusement Rides. Proceedings of the SIGCHI Conference on Human Factors in Computing Systems (New York, NY, USA, 2011), 73-82.

32. Marshall, J. and Tennent, P. 2013. Mobile Interaction Does Not Exist. CHI '13 Extended Abstracts on Human Factors in Computing Systems (New York, NY, USA, 2013), 2069-2078.

33. Moen, J. 2006. KinAesthetic movement interaction: designing for the pleasure of motion. KTH.

34. Mueller, F., Edge, D., Vetere, F., Gibbs, M.R., Agamanolis, S., Bongers, B. and Sheridan, J.G. 2011. Designing sports: a framework for exertion games. Proceedings of the SIGCHI Conference on Human Factors in Computing Systems (New York, NY, USA, 2011), 2651-2660.

35. Mueller, F. and Isbister, K. 2014. Movement-based Game Guidelines. Proceedings of the SIGCHI Conference on Human Factors in Computing Systems (New York, NY, USA, 2014), 2191-2200.

36. Mueller, F., Toprak, C., Graether, E., Walmink, W., Bongers, B. and van den Hoven, E. 2012. Hanging off a Bar. CHI '12 Extended Abstracts on Human Factors in Computing Systems (New York, NY, USA, 2012), 1055-1058.

37. Salen, K. and Zimmerman, E. 2003. Rules of Play: Game Design Fundamentals. The MIT Press.
38. Schank, R.C. and Hughes, L.P. 1992. Discovering scientific questions. International Studies in the Philosophy of Science. 6, 1 (Jan. 1992), 57-59.

39. Schell, J. 2008. The art of game design a book of lenses. Elsevier/Morgan Kaufmann.

40. Schmidt, R.A. and Wrisberg, C.A. 2008. Motor Learning and Performance. Human Kinetics.

41. Schredl, M. 2010. Nightmare frequency and nightmare topics in a representative German sample. European Archives of Psychiatry and Clinical Neuroscience. 260, 8 (Dec. 2010), 565-570.

42. Shotton, J., Sharp, T., Kipman, A., Fitzgibbon, A., Finocchio, M., Blake, A., Cook, M. and Moore, R. 2013. Real-time human pose recognition in parts from single depth images. Commun. ACM. 56, 1 (Jan. 2013), 116-124.

43. Švelch, J. 2014. Comedy of Contingency: Making Physical Humor in Video Game Spaces. International Journal of Communication. 8, 0 (Sep. 2014), 23.

44. Swink, S. 2008. Game Feel: A Game Designer's Guide to Virtual Sensation. CRC Press.

45. Tassa, Y., Mansard, N. and Todorov, E. 2014. ControlLimited Differential Dynamic Programming. Proc. ICRA'14 (2014).

46. The Ido Portal Method. http://www.idoportal.com/videos/the-ido-portalmethod-israel. Accessed: 2014-09-13.

47. Yee, N. and Bailenson, J. 2007. The Proteus Effect: The Effect of Transformed Self-Representation on Behavior. Human Communication Research. 33, 3 (2007), 271-290.

48. 2013. 6180 the Moon. Turtle Cream.

49. 2014. Bounden. Game Oven.

50. 2014. $i b b \& o b b$. Sparpweed.

51. 2008. Little Big Planet. Sony Computer Entertainment.

52. 1983. Mario Bros. Nintendo.

53. 2011. Michael Phelps: Push the Limit. Microsoft.

54. 2008. QWOP. Foddy.net.

55. 2011. Rochard. Sony Online Entertainment.

56. 2006. Toribash. Nabi Studios.

57. 1966. Twister. Milton Bradley Company.

58. 2011. Twister Mania - Xbox 360. Majesco. 